\title{
Cortical Vein Thrombosis as a Mimic for Isolated Cortical Subarachnoid Hemorrhage and Transient Ischemic Attack
}

\author{
Jane G. Morris Marc Fisher Raphael A. Carandang \\ Department of Neurology, UMass Memorial Medical Center, University of \\ Massachusetts Medical School, Worcester, Mass., USA
}

\section{Key Words}

Cortical vein thrombosis - Isolated cortical subarachnoid hemorrhage $\cdot$ Transient ischemic attack

\begin{abstract}
Isolated cortical subarachnoid hemorrhage is rare and poorly understood. Differential diagnoses and proposed pathophysiology vary widely and the diagnostic work-up for these patients who present with transient ischemic attack-like episodes and characteristic imaging findings is still unclear. We report a case of isolated subarachnoid hemorrhage and transient neurologic deficits due to isolated cortical vein thrombosis that was not detected by noninvasive tests. A 75-year-old woman with a history of a lobar intracerebral hemorrhage presented to the Academic Medical Center with sudden-onset transient left upper extremity weakness. Head CT showed a linear hyperdensity in the right precentral gyrus suggestive of isolated subarachnoid hemorrhage. MRI showed susceptibility in the corresponding area. CT angiogram and MRV showed no evidence of a venous thrombosis. The main outcome measures were results of computerized tomography and $\mathrm{CT}$ angiogram, magnetic resonance parenchymal and vascular imaging, angiography findings and clinical follow-up at 3 months. Cortical vein thrombosis was detected on conventional angiography. MRI was negative for microhemorrhages. The patient was anticoagulated and had no recurrences of her symptoms. We conclude that cortical vein thrombosis can present as isolated subarachnoid hemorrhage and transient ischemic attack-like episodes and may require angiography for definitive diagnosis.
\end{abstract}




\begin{tabular}{l|l|l|l} 
Case Reports in & $\begin{array}{l}\text { Case Rep Neurol 2010;2:63-68 } \\
\text { Dol: } 10.1159 / 000315651\end{array}$ & Published online: June 1, 2010 & $\begin{array}{l}\text { @ 2010 S. Karger AG, Basel } \\
\text { ISSN 1662-680X } \\
\text { www.karger.com/crn }\end{array}$ \\
\hline
\end{tabular}

\section{Introduction}

Isolated convexity subarachnoid hemorrhage is a rare form of subarachnoid hemorrhage and has only been described in case reports and series [1]. Presenting symptoms have been described as nonspecific and include headache, focal neurological deficits, seizures and altered mental status. Prognosis is generally favorable in a majority of cases reported. Varied etiologies reported include amyloid angiopathy, reversible vasoconstrictive syndrome, posterior reversible leukoencephalopathy, dural arteriovenous fistula or arteriovenous malformation, dural or cortical venous sinus thrombosis and vasculitis.

Recent literature [2] suggests that this may be a new or distinct clinical entity and may be related to cortical spreading depression, however the diagnostic work-up of these patients has not been uniform nor has their treatment. We describe a patient who presented with transient focal neurological deficits and characteristic radiographic findings of isolated convexity subarachnoid hemorrhage whose noninvasive diagnostic work-up ultimately required angiography to make the definitive diagnosis of cortical vein thrombosis and who responded to therapy with anticoagulation.

\section{Case Report}

A 75-year-old woman with a history of hypertension, Bell's palsy and left temporal lobe intracerebral hemorrhage two years prior presented with sudden-onset left upper extremity weakness lasting approximately $10 \mathrm{~min}$. She initially noted her left arm to become floppy and difficult to control. This was followed by paresthesias over her arm and en route to the hospital she developed a mild right-sided headache. On arrival at the emergency room her symptoms had resolved. Initial head CT showed a linear hyperdensity in the right precentral gyrus suggestive of focal subarachnoid hemorrhage. Her blood pressure on admission was not elevated and she had no coagulopathy or thrombocytopenia. Her home medications included Valproic acid, Citalopram, Lisinopril and Aspirin but she denied any new medications. CT angiogram was normal. MRI of the brain showed FLAIR hyperintensity and susceptibility in the area corresponding to the CT hyperdensity (fig. 1). There were no microhemorrhages on the gradient echo sequence, though changes from the prior intracerebral hemorrhage were noted. MRV showed no evidence of venous thrombosis. EEG was normal. During her hospitalization she had several recurrent episodes of transient left upper extremity paresis. Repeat head CTs did not show recirculation of blood products typically seen in subarachnoid hemorrhage. Cerebral angiogram demonstrated filling defects of multiple cortical veins with patent dural sinuses (fig. 2 ). She was started on a heparin drip and warfarin therapy. One further event occurred when the patient was being transitioned from heparin drip to enoxaparin in preparation for discharge. Repeat EEG was normal. She was discharged home on warfarin with no residual deficits. On follow-up at 3 months she denied any recurrences since discharge.

\section{Discussion}

The differential diagnosis in our patient included amyloid angiopathy given her age and the history of previous lobar hemorrhage. Cerebral amyloid angiopathy has been described as an etiology for transient neurological deficits and focal subarachnoid hemorrhage as one of its less common presentations and is possibly an underestimated cause [3]. Some case series describe subsequent lobar hemorrhages following cortical subarachnoid hemorrhage [4]. One study reports 2 patients who 20-33 days after initially presenting with isolated subarachnoid hemorrhage developed large subcortical hematomas [5]. Our patient's MRI showed no evidence of microhemorrhages and she has not exhibited any subsequent hemorrhages even while on therapeutic warfarin for 90 days since discharge. Focal seizures were deemed less likely given the unremarkable serial 
EEGs and lack of response to anticonvulsant medication. Given that she was taking a selective serotonin reuptake inhibitor, another consideration would be reversible vasoconstrictive syndrome [6]; however her headache was mild and not thunderclap in character and her angiography did not show any vasculopathy. Our patient did experience aura-like paresthesias down her left arm following the onset of weakness and did have a mild right-sided headache on initial presentation despite no history of migraine headaches in the past. This is compatible with the theory by Izenberg et al. of this being a cortical spreading depression triggered by subarachnoid blood or blood products as has been demonstrated in animal studies [2]. While these are good explanations of the pathophysiology, they do not offer insights into the etiology of the subarachnoid hemorrhage. Furthermore none of their patients underwent conventional angiography. A recently published case series of 29 patients with convexal subarachnoid hemorrhage emphasizes the diverse etiologies of this clinical-radiographic syndrome and attempts to characterize them further in those younger and older than 60 years, emphasizing cerebral amyloid angiopathy as the most common etiology in those 60 years or older [7]. However in that study only $55 \%$ of patients underwent conventional angiography and this is a limitation that the authors acknowledge.

The persistence of the cortical hyperdensity on CT or 'cord sign' and lack of recirculation of the small amount of cortical subarachnoid blood affords a clue that it is not subarachnoid hemorrhage but likely thrombosis with siderosis. Radiographic diagnosis of isolated cortical vein thrombosis is difficult secondary to the diminutive size of the veins, anatomic variation involved and the rapid compensation by venous collaterals and recanalization $[8,9]$. MRI can be diagnostic if it shows thrombus in the superficial vein(s), as well as secondary changes such as surrounding FLAIR hyperintensity from gyral edema resulting from venous congestion [9], and some authors feel that spin-echo T1-weighted sagittal, double-echo T2-weighted axial and axial FLAIR images are adequate for the diagnosis $[10,11]$, but in the case of our patient these sequences did not reveal the cortical vein thrombosis. MRV is limited due to both wide anatomic variation and the small size of cortical veins and in our patient only showed patent dural venous sinuses. Angiography was considered the diagnostic gold standard of choice to diagnose isolated cortical vein thrombosis previous to improvements in MRI, but no systematic comparative studies are available [9-11].

The decision to order a conventional angiogram with its invasiveness and attendant risk was felt to be justified by the recurrence of symptoms in the setting of therapeutic anticonvulsant levels and lack of evidence of electrographic seizures. Many of the prominent etiologies reported including vasculitis, reversible vasoconstriction syndrome, dural or cortical venous sinus thrombosis and dural arteriovenous fistula or arteriovenous malformation [12] may require angiography for diagnosis and sometimes present opportunities for treatment in the angiography suite. Like all invasive procedures risks and benefits need to be weighed, but angiography should be considered in the work-up of isolated cortical subarachnoid hemorrhage in the setting of recurrent transient ischemic attack-like episodes in patients whose MRIs are inconclusive. 


\begin{tabular}{l|l|l|l} 
Case Reports in & $\begin{array}{l}\text { Case Rep Neurol 2010;2:63-68 } \\
\text { Dol: } 10.1159 / 000315651\end{array}$ & Published online: June 1, 2010 & $\begin{array}{l}\text { ○ 2010 S. Karger AG, Basel } \\
\text { ISSN 1662-680X } \\
\text { www.karger.com/crn }\end{array}$ \\
\hline
\end{tabular}

Fig. 1. a CT scan showing isolated convexal subarachnoid hemorrhage with a hyperdense 'cord' sign in the right prefrontal area, b susceptibility MRI corresponding with thrombus, c FLAIR showing area of hyperintensity in gyrus, and $\mathbf{d}$ ADC MRI showing small area of venous infarction.
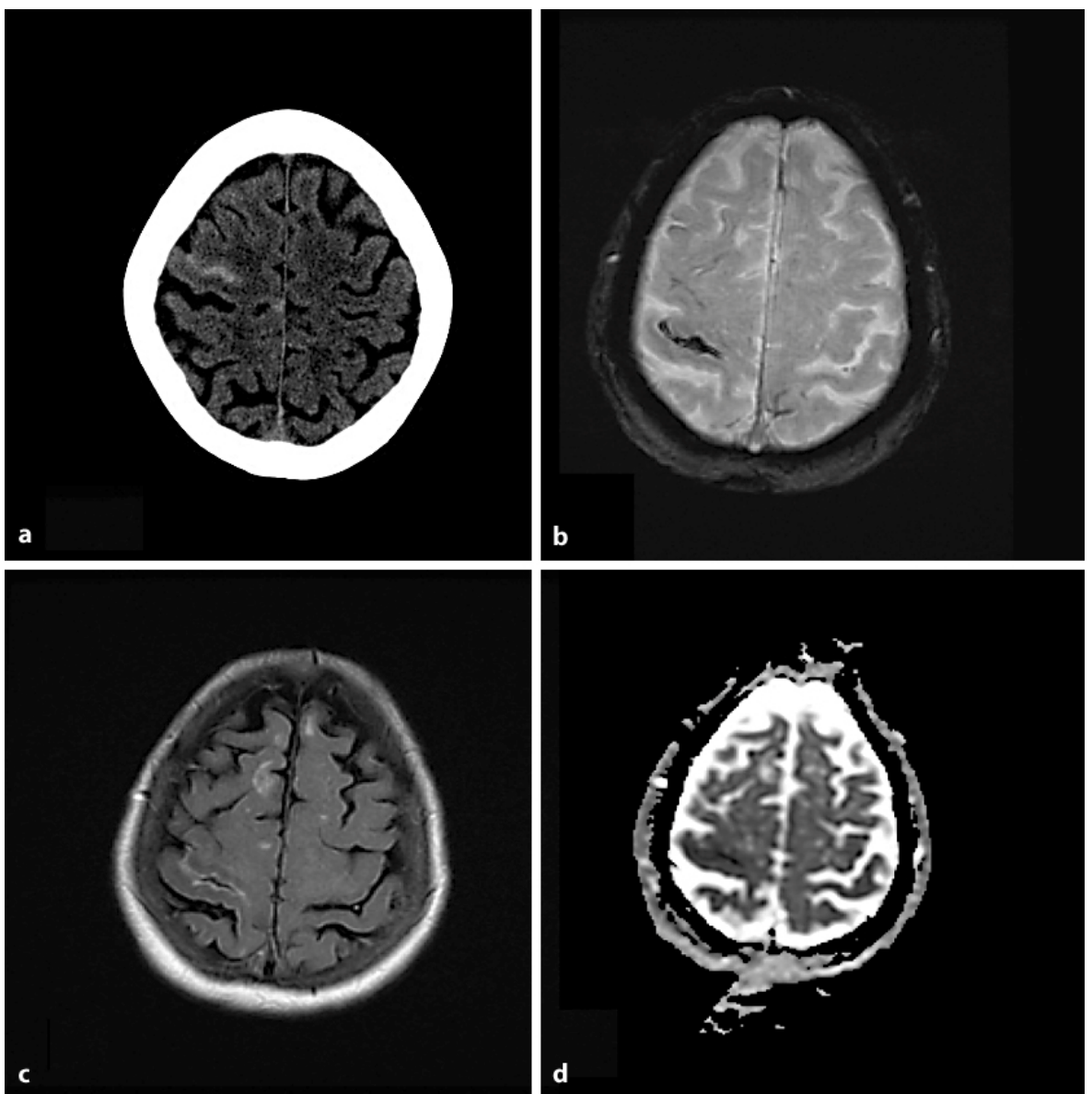


\begin{tabular}{l|l|l|l} 
Case Reports in & $\begin{array}{l}\text { Case Rep Neurol 2010;2:63-68 } \\
\text { Dol: } 10.1159 / 000315651\end{array}$ & Published online: June 1, 2010 & $\begin{array}{l}\text { ○ 2010 S. Karger AG, Basel } \\
\text { ISSN 1662-680X } \\
\text { www.karger.com/crn }\end{array}$ \\
\hline
\end{tabular}

Fig. 2. Angiogram (oblique view) showing engorged cortical veins with absence of flow (arrows) prior to entry into the sagittal sinus.

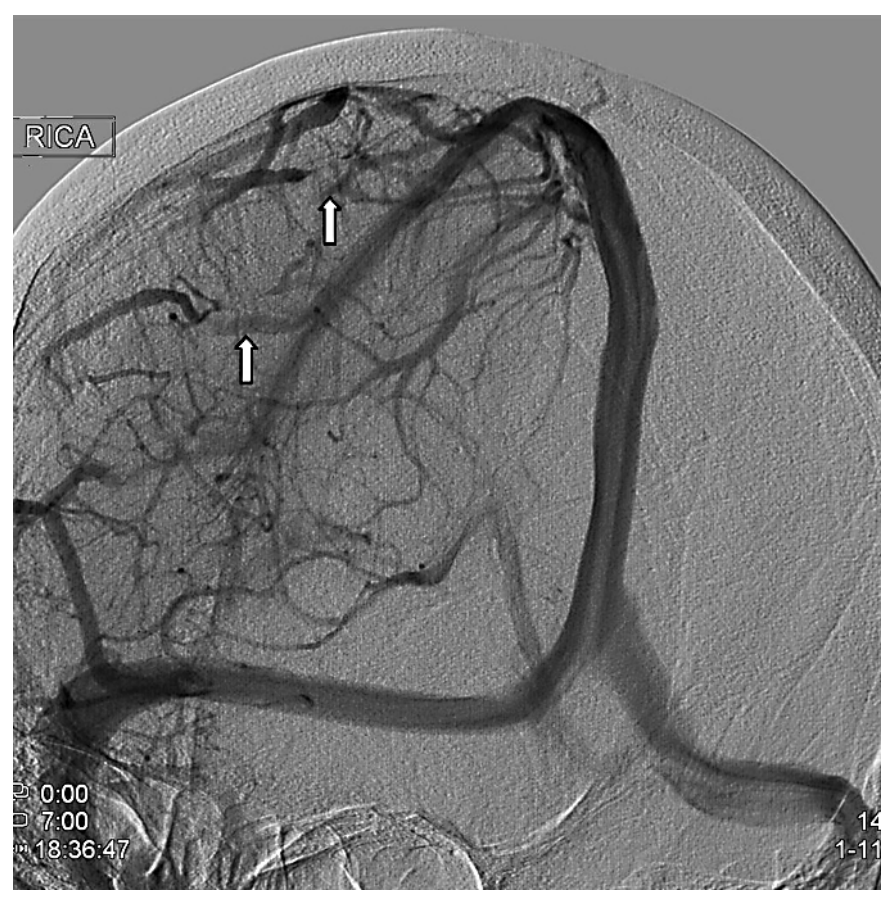




\begin{tabular}{l|l|l|l} 
Case Reports in & $\begin{array}{l}\text { Case Rep Neurol 2010;2:63-68 } \\
\text { Dol: } 10.1159 / 000315651\end{array}$ & Published online: June 1, 2010 & $\begin{array}{l}\text { @ 2010 S. Karger AG, Basel } \\
\text { ISSN 1662-680X } \\
\text { www.karger.com/crn }\end{array}$ \\
\hline
\end{tabular}

\section{References}

1 Refai D, Botros JA, Strom RG, Derdeyn CP, Sharma A, Zipfel GL: Spontaneous isolated convexity subarachnoid hemorrhage: presentation, radiological findings, differential diagnosis and clinical course. J Neurosurg 2008;109:1034-1041.

-2 Izenberg A, Aviv R, Demaerschalk B, Dodick D, Hopyan J, Black S, Gladstone D: Crescendo transient aura attacks: a transient ischemic attack mimic caused by focal subarachnoid hemorrhage. Stroke 2009;40:3725-3729.

-3 Greenberg SM, Vonsattel JPG, Stakes JW, Gruber M, Finklestein SP: The clinical spectrum of cerebral amyloid angiopathy: Presentations without lobar hemorrhage. Neurology 1993;43:2073-2079.

-4 Brunot S, Fromont A, Ricolfi F, Moreau T, Griroud M: Focal subarachnoid hemorrhage and cerebral amyloid angiopathy: A non-fortuitous association. Rev Neurol 2010;166:83-89.

-5 Katoh M, Yoshino M, Araoka K, Aoki T, Immura H, Kashiwazaki D, Tahano K, Aida T: A restricted subarachnoid hemorrhage in the cortical sulcus in cerebral amyloid angiopathy: Could it be a warning sign? Surg Neurol 2007;68:457-460.

6 Ducros A, Boukobza M, Porcher R, Sarov M, Valade D, Bousser MG: The clinical and radiological spectrum of reversible cerebral vasoconstriction syndrome. A prospective series of 67 patients. Brain 2007;130:3091-3101.

-7 Kumar S, Goddeau RP, Caplan LR, et al: Atraumatic convexal subarachnoid hemorrhage. Neurology 2010;74:893-899.

8 Urban P, Muller-Forell W: Clinical and neuroradiological spectrum of isolated cortical vein thrombosis. J Neurol 2005;252:1476-1481.

-9 Boukobza M, Crassard I, Bousser MG, Chabriat H: MR imaging features of isolated cortical vein thrombosis: diagnosis and follow up. AJNR Am J Neuroradiol 2009;30:344-348.

10 Chang R, Friedman DP: Isolated cortical venous thrombosis presenting as subarachnoid hemorrhage: a report of three cases. AJNR Am J Neuroradiol 2004;25:1676-1679.

11 Linn J, Michl S, Katja B, Pfefferkorn T, Dichgans M, Bruchmann H: Cortical vein thrombosis: the diagnostic value of different imaging modalities. Neuroradiology 2010, Epub ahead of print.

12 Rathakrishnan R, Sharma VK, Chan BPL: Isolated cortical vein thrombosis in a patient with arteriovenous malformation. J Clin Neurosci 2009;16:856-857. 